\title{
Social Ties in a Public Good Experiment
}

\author{
by \\ Frans van Dijk \\ Joep Sonnemans \\ Frans van Winden
}

\begin{abstract}
The formation of social ties is examined in an experimental study of voluntary public good provision. The experiment consists of three parts. In the first part the value orientation (attitude to a generalized other) is measured. In the second part couples play 25 periods of a public good game. In the third part the attitudes of subjects to their partners in the public good game is measured. The concept of a social tie is operationalized as the difference between the measurements in the first and third parts. Evidence for the occurrence of social ties is found. These ties depend on the success of the interaction in the public good game.
\end{abstract}

Keywords: Public good, social ties, experiment

JEL: C91, H41, A13

November 1996

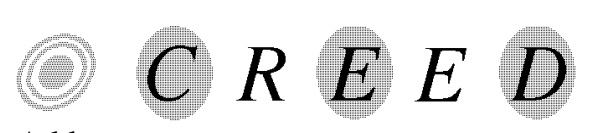

Address:

CREED Department of Economics

University of Amsterdam

Roetersstraat 11, 1018 WB Amsterdam

The Netherlands

Tel. 31-205254298

Fax. 31-205255283

E-mail: fransd@fee.uva.nl

*Financial support by the Netherlands' Organization for Scientific Research (NWO) is gratefully acknowledged. We thank Paul van Lange and Claudia Keser for their comments in an early phase of the project and Otto Perdeck for his programming work. We also thank Catherine Eckel, Martin Sefton and participants of the AWEE'96 and ESA '96 for their comments. 


\section{Introduction}

In economics the usual assumption is that individuals have identical preferences. This has also been the maintained hypothesis in public goods experiments. However, at least in this area of research there seems to be a growing consensus that different types of individuals exist (Ledyard, 1995). There are subjects who (almost) never contribute to the public good in such an experiment, when it is a dominant strategy not to do so, whereas others (almost) always contribute. More direct, independent evidence of different subject types is provided by so-called "social value orientation" tests, developed by psychologists, where preferences of individuals for distributions of outcomes for themselves and others are derived using the decomposed game technique (see e.g. Liebrand, 1984). According to these tests most subjects can be classified as follows, using the terminology of the tests: "individualists", who try to maximize their own payoff; "cooperators", trying to maximize the joint payoff to themselves and others; and "competitors", who try to maximize the differential between their own payoff and that of others. Many studies have shown the predictive validity of these tests, inside as well as outside the laboratory. For successful applications in economic experiments, see Offerman et al.. (1996), Sonnemans et al. (1996) and Offerman (1996). Cooperators are inclined to contribute more to the public good than individualists, for instance.

In a way, the aforementioned value orientation tests can be said to measure the attitude of an individual with respect to the interests (well-being) of a generalized other, since subjects do not know the other subject they are paired with in the game that is used for measurement. Clearly, attitudes may differ, though, regarding individuals they get to know better through interaction. In this respect the sociological notion of a "social tie" is important ${ }^{1}$. According to this literature social ties develop through prolonged interaction, and erode when the interaction ends (Granovetter, 1985, Coleman, 1990). The strength of a tie is often seen as multi-dimensional, and defined in terms of "emotional intensity" (the affective component), time spent together, mutual confidence, reciprocal services and so forth (Granovetter, 1973). However, following Baumeister and Leary, 1995, the affective component - sentiments - can be considered to be the key element. In addition, as suggested by Coleman (1990) and Granovetter (1992), ties are largely the unconscious by-product of social interaction. Through these interactions persons form positive or negative sentiments about each other, dependent on whether the interaction is valued positively or negatively (cf. Homans, 1950, 1961, Feld, 1986, Fararo, 1989).

Then, a natural way of defining social ties and their intensity is to characterize them in terms of the sentiments that individuals have with respect to specific other individuals, where sentiments concern the extent to which they care about the well-being of those others. This shows the relationship between the (psychological) concept of a social value orientation and the (sociological) concept of a social tie. The latter differs from the first mainly in so far as a specific other is focused

\footnotetext{
${ }^{1}$ See, e.g., Coleman, 1990, Feld, 1986, Granovetter, 1973, Wellman, 1988.
} 
on, and not a generalized other. In both cases a formalization in terms of utility interdependence is suggested.

Social ties can be of great relevance to economic performance. As Granovetter, 1985, argues, economic behavior is embedded in networks of interpersonal relations, and this has profound effects on economic interaction. Examples he mentions are the generation of trust and honesty, leading to a reduction of transaction costs, and the transmission of information. In a theoretical study, Van Dijk and Van Winden (forthcoming) show that taking account of the development of social ties in the voluntary provision of public goods leads to results that are in stark contrast with the standard model. It is, therefore, of interest to examine the occurrence and effects of social ties in economic experiments.

As noticed, the existence of different types of subjects and the importance thereof for the explanation of contributions in public good games, has been shown by experiments using a value orientation test. The main goal of this paper is to go a step further by studying whether also the development of social ties can be established in an economic experiment. We do this by applying the same value orientation test (the so-called Ring-test) twice, before and after a two-person public good experiment. In the first Ring-test subjects play against an anonymous other subject, whereas in the second test they play against the person they interacted with in the public good experiment. The difference between the two tests is taken to measure the establishment of a social tie ${ }^{2}$.

The first test is also used to replicate the earlier findings that subjects differ in preferences and that these differences affect their contributions to the public good. In contrast with existing studies we will not group individuals into types, but do this analysis at the individual level, however. To investigate the stability of the test and the crucial nature of interaction for the development of a social tie, a control group of subjects is used that are faced with an individual decision-making experiment, instead of the public good experiment, in between the two tests. Furthermore, we investigate whether evidence can be obtained for the presumed underlying mechanism of social ties, which concerns the success of the interaction for the subjects involved. Several conditions are used to check the robustness of the results.

Our main result is that evidence for the occurrence of social ties is found and that these ties depend on the success of the interaction in the public good game.

The organization of the paper is as follows. Section 2 goes into the design and the procedures of the Ring-tests and the individual decision-making and public good experiments. Section 3 presents the results. Section 4 concludes.

\footnotetext{
${ }^{2}$ In the aforementioned sociological literature a social tie is generally seen as a mutual, two-sided relationship. The tie between two individuals $i$ and $j$ would then consist of $i$ 's sentiments about $j$ and $j$ 's sentiments about $i$, both reflected by differences in the Ring-tests. However, for ease of exposition, we will speak of $i$ 's social tie with $j$ without immediate reference to $j$ 's sentiments about $i$, and vice versa. It is noted that sentiments are often not symmetric (see Wellman, 1988).
} 


\section{Design}

In 10 sessions a total number of 140 subjects participated, of which about 2/3 were students of economics. On average 51.2 Dutch guilders (approximately US\$ 34) were earned by the subjects in about two hours.

The experiment was completely computerized, and took place in the CREED-laboratory of the University of Amsterdam. The experiment comprised 3 conditions, and each session consisted of three parts (see table 1). In the first and third part of each session the Ring-test was administered, while the second part was either a two-person public good experiment (experimental conditions) or an individual decision-making experiment (control condition). We will now discuss these parts in more detail.

Table 1. The design of the study.

\begin{tabular}{|l|l|l|l|}
\hline Part 1 & $\begin{array}{l}\text { Equal endowment } \\
\text { condition }\end{array}$ & $\begin{array}{l}\text { Unequal endowment } \\
\text { condition }\end{array}$ & Control condition \\
& $\begin{array}{l}\text { Ring-test in which a subject } \\
\text { is coupled with an } \\
\text { unknown other (randomly } \\
\text { determined) }\end{array}$ & $\begin{array}{l}\text { Ring-test in which a subject } \\
\text { is coupled with an } \\
\text { unknown other (randomly } \\
\text { determined) }\end{array}$ & $\begin{array}{l}\text { Ring-test in which a subject } \\
\text { is coupled with an } \\
\text { unknown other (randomly } \\
\text { determined) }\end{array}$ \\
\hline Part 2 & $\begin{array}{l}\text { Public good experiment in } \\
\text { which both subjects have to } \\
\text { divide 10 markers between } \\
\text { a private and a public } \\
\text { account }\end{array}$ & $\begin{array}{l}\text { Public good experiment in } \\
\text { which one subject has to } \\
\text { divide 8 markers and the } \\
\text { other 12 markers between a } \\
\text { private and a public } \\
\text { account }\end{array}$ & $\begin{array}{l}\text { Individual decision-making } \\
\text { experiment }\end{array}$ \\
\hline Part 3 & $\begin{array}{l}\text { Ring-test in which a subject } \\
\text { is coupled with the same } \\
\text { subject as in part 2 }\end{array}$ & $\begin{array}{l}\text { Ring-test in which a subject } \\
\text { is coupled with the same } \\
\text { subject as in part 2 }\end{array}$ & $\begin{array}{l}\text { Ring-test in which a subject } \\
\text { is coupled with an } \\
\text { unknown other (randomly } \\
\text { determined) }\end{array}$ \\
\hline Participants: & 52 subjects in 4 sessions & 58 subjects in 4 sessions & 30 subjects in 2 sessions \\
\hline
\end{tabular}

Parts 1 and 3: Ring-test

In the first and third part of the experiment each subject was coupled with one other subject, and had to make 32 choices between two 'own-other' payoff combinations. Each own-other payoff combination allocates an amount of money to the decision maker and to the subject with which the individual is linked. During the experiment, subjects did not receive any feedback about the other's choices. The 32 pairs of allocations lie on a circle with the origin as centre and a radius of 500 cents (which explains the name of the test). The horizontal axis measures the amount of money allocated to oneself $(x)$ and the vertical axis the amount of money allocated to the other (y). For all outcomes $x^{2}+y^{2}=500^{2}$. As a result, the total amount to be allocated $(x+y)$ is not constant over combinations. For example, subjects have to choose between the combination 397 cents for self and 304 cents for the other (total of 701 cents) and the combination 433 cents for self and 250 cents for the other (total of 683 cents). In Appendix 1 the 32 questions are listed. Each allocation can be considered as a vector. If for each subject the 32 preferred allocations are added, the angle 
of the resulting vector with the horizontal axis is a measure of the extent the individual cares about other. The length of this vector is a measure of the consistency of the 32 choices (the maximum length is 1000). For example, the vector of a $100 \%$ consistent individualist will be $(1000,0)$, which means 1000 cents for herself and nothing for the other, corresponding with an angle of $0^{\circ}$.

The test we used is an adaptation of the one developed by Liebrand (1984). Originally the goal of this test is to measure "social value orientation", which is seen as a stable psychological trait. Psychologists have used this test intensively and recently experimental economists have begun using this test as well (Offerman et al., 1996, Sonnemans et al., 1996). On the basis of this test subjects are classified as individualistic (only concerned about their own payoff), cooperative (concerned about the sum of own and other's payoff), altruistic (only concerned about the other's payoff), competitive (concerned about the difference between own and other's payoff) or aggressive (only concerned in minimizing the earnings of the other). For an elaborate discussion of this test we refer to Liebrand (1984) and Offerman et al. (1996). To make a more precise measurement possible, a test with 32 (instead of 24) questions was used. In this adapted Ring-test the outcomes are not equally spaced on the circle (as in the original test) but distributed in such a way that the most common value orientations (individualistic, cooperative and competitive) are measured more precisely than the rare other orientations 3 .

In the first part of the experimental conditions and in the third part of the control condition, subjects did not know with whom they were paired. They were only informed that the pairing would stay the same throughout the 32 decisions. In the third part of the experimental conditions subjects again did not know the identity of their partner, but they knew that they were coupled to the same subject as in part 2 of the experiment (the public good experiment). In these conditions subjects could still browse through their decisions and results concerning the public good experiment. To make it less clear to the subjects that the 32 questions were the same as in part 1, the order of the questions was changed in part 3.

As noted, in this experiment the Ring-test is used in a different way than in other studies. In the first part of the experiment it measures the attitude of the subject towards an unknown other (social value orientation), like in the original Ring-test. In the third part of the experimental conditions, the test measures the attitude of the subject to her/his partner in the public good experiment (social tie). In this way we can learn whether the public good experiment changed the attitudes of the subjects. If they like (dislike) their partner more than they like or dislike others in general, they would sacrifice more money to help (hurt) the other subject.

\section{Part 2: Public good experiment}

In the second part of the two experimental conditions 25 periods of a public good game were played. Subjects were randomly coupled and these two-person groups stayed constant for all 25

\footnotetext{
${ }^{3}$ Measurement will be more precise if the distance between the alternative outcomes is smaller. However, this means more questions which may decrease the concentration and motivation of the subjects. Our setup compromises between these two effects.
} 
periods. In each period a subject had to distribute 10 markers (in the equal endowment condition) or 8 or 12 markers (in the unequal endowment condition) over two activities $X$ and $Y$. Activity $X$ generated earnings exclusively for the subject her/himself (private account), whereas activity $Y$ generated earnings for both group members (public account). For each subject the endowment was the same in all periods. Every marker in the public account earned 14 cents for both group members, while the value of $i$ markers in the private account was: $28 * i-i^{2}$. Fixed costs of 110 cents were substracted each period.

The first period started after everybody had finished the computerized instructions. Each period subjects had to type in how many markers they wanted to spend on activities $X$ and $Y$. After each period they received feedback about the total number of markers both spent on activity $Y$ and their own earnings. In the lower part of the screen the decisions and results of previous periods were displayed. Subjects could access information about all previous periods by using the page-up and page-down keys.

The Nash equilibria of the one shot games are characterized by dominant strategies. The dominant strategy in the equal endowment condition is to put 3 markers in the public account and 7 markers in the private account. In the unequal endowment condition the dominant strategy for subjects with 12 markers is to put 5 markers in the public account and 7 in the private account, and for subjects with 8 markers to put 1 into the public and 7 in the private account. In both conditions the Pareto optimal solution is that the players put all markers into the public account. In both conditions both players earn 121 cents in the Nash equilibrium and 170 cents in the Pareto optimal solution ${ }^{4}$.

\section{Part 2: Individual decision-making (Control Condition)}

The second part of the control condition is an individual decision-making experiment (a computerized sequential search experiment) which has the same duration as the public good experiment. The mental resources of subjects that are required are also comparable with those in the public good experiment. The crucial difference with the public good experiment is that it is an individual experiment with no interaction between subjects.

The control condition was included in the design to check the stability of the Ring-test measures. A change in Ring-test measures between the first and the third part of the experimental conditions cannot be attributed unambiguously to the public good experiment without a control condition. Alternative explanations based on the repetition of the test and the duration of the experiment, leading to tiredness or boredom, could then perhaps be formulated. And it would be impossible to differentiate between these explanations.

\section{Procedures}

\footnotetext{
${ }^{4}$ This invariance result is not caused by our payoff schedule, but holds generally, see for example Warr (1982).
} 
Subjects were recruited by announcements on information boards in university buildings and an advertisement in the university newspaper. After all subjects were seated, computerized instructions for the first part (Ring-test) were started. The instructions contained some questions to check understanding. After the instructions all subjects took the 32 decisions of the test. Subjects did not receive any feedback about the results of part 1 until the whole experiment was finished. Information about parts 2 and 3 was given after the end of, respectively, part 1 and part 2.

After part 1, the instructions of part 2 were started. A translation of the instructions is provided in Appendix 2. The payoff structure of the public good experiment was explained with a table on the computer screen and on a handout, and subjects had to calculate some outcomes to check understanding. This table was also projected on the wall to assure subjects that everybody had the same table. In addition, a handout with a normal form table of the payoff structure was distributed (see Appendix 3). The number of periods (25) was also public knowledge. In the control condition part 2 was an individual decision-making experiment (a computerized sequential search experiment). Details about this experiment can be obtained from the authors.

In part 3 subjects had to make again the 32 decisions of the Ring-test, but now in a different order. In the experimental conditions subjects were coupled with the same participants as in the second part of the experiment, and they were informed about this. The results of all periods of part 2 remained accessible to them on the lower part of the screen. In the control group subjects were told that they were randomly coupled, and the lay-out of the screen was exactly the same as in part 1 .

After part 3 the subjects filled in a short questionnaire and were subsequently paid, one at a time, in another room.

\section{Results}

\section{Reliability and validity of the instruments}

Before we can investigate the influence of the public good game on the development of social ties, we first need to check the reliability and validity of the Ring-test. Each test provides two numbers: the angle and the consistency of the choices made. In some cases the consistency was very low. A random sequence of choices results in an average consistency of 500. Following Liebrand (1984) measurements with a consistency lower than 600 were not included in the analyses (15 of the first part and 12 of the third part; in total 23 subjects had a consistency lower than 600 in at least one part). As one would expect, consistency is typically higher in the third part than in the first (Wilcoxon test on all 140 subjects, 2-tailed $\mathrm{P}=.0072$, Wilcoxon test on 117 subjects with both consistencies $>600,2$-tailed $P=$. 0108). The control group and the experimental groups do not differ in the Ring-test of the first part. The mean angle of the first ringtest is $3^{\circ}$, and $95 \%$ of the angles is located between $-45^{\circ}$ and $45^{\circ}\left(80 \%\right.$ between $-20^{\circ}$ and $\left.20^{\circ}\right)$.

The Ring-test results of the first and third part of the control condition show the reliability of the test. The value orientations (angles of the resulting vectors) in these parts do not significantly differ (Wilcoxon 2-tailed $\mathrm{P}=.35$ ), and both measurements are highly correlated (the 
Pearson correlation is .8728 , and the Spearman rank correlation is .9188). This confirms that the Ring-test is a reliable instrument, at least in the short term.

The Ring-test of the first part is supposed to measure the social value orientation of the subject. Its outcome should correlate with the behavior of the subject in the public good game. To make the behavior of subjects with different endowments comparable, we look at the number of markers subjects allocated to the public account minus the number they should have allocated according to their dominant strategy (for all subjects the dominant strategy is to allocate 7 markers to the private account; see the previous section). We find statistically significant correlations with the first as well as the first 5 decisions in the public good game (the Spearman rank correlations are, respectively, .2836 and .3016, $\mathrm{P}<.01)$. The correlation with all decisions in the public good game is lower (the Spearman rank correlation is .1871 which is not statistically significant). This is in accordance with earlier findings (e.g., Offerman et al. 1996) and with the idea that when subjects learn to know each other through interaction, the social value orientation starts to play a less important role, whereas the importance of social ties increases. The correspondence of the first Ring-test and the decisions in the early periods of the public good game confirms the validity of the measurement of the social value orientation.

The social tie that may be created by the public good game is measured by comparing the results of the second Ring-test with those of the first test: an increased (decreased) angle indicates a positive (negative) social tie. To check whether this measurement is related with the concept as used by sociologists, the following question was asked in the questionnaire after the experiment: "If the second part of the experiment were to be repeated, would you like to continue with the participant you were coupled with, or rather with an arbitrary other?". This is a type of question sociologists freqently use in their studies. The 7-point answering scale was dichotomized. Subjects who liked to have a new partner have a more negative social tie than subjects who wanted to stay with their present partner (Mann-Whitney ranktest 2-tailed $\mathrm{P}=.0564$ ). This implies that our measurement of social ties is indeed related to the sociological concept.

\section{The public good game}

Figure 1 shows the contributions to the public account in excess of the dominant strategy, by period and condition. We make the following observations. The first thing which strikes the eye is that subjects contribute substantially more than the Nash-equilibrium, and that the contributions rapidly decline in the final periods. Both phenomena have been observed in many other public good experiments as well (see Ledyard, 1995). Another interesting observation is that subjects with a 12-markers endowment in the Unequal Endowment (UE-12) condition contribute significantly less (in excess of their dominant strategy) than the subjects with an 8-markers endowment in the Unequal Endowment (UE-8) condition do (Wilcoxon ranktest 2-tailed 
$\mathrm{P}=.0000)^{5}$ and also less than the subjects in the Equal Endowment (EE) condition do (Mann Whitney rank test 2-tailed $\mathrm{P}=.0134)$. There is no statistical significant difference between UE-8 and EE. These results are in line with the tentative conjecture in the literature that heterogeneity lowers the rate of contribution (Ledyard, 1995, p 160).

In the EE condition the Nash equilibrium was played in $10.5 \%$ and the Pareto optimal solution in $15.6 \%$ of the periods. In the UE condition the Nash equilibrium was played in $13.4 \%$ and the Pareto optimal solution in $10.5 \%$ of the periods.

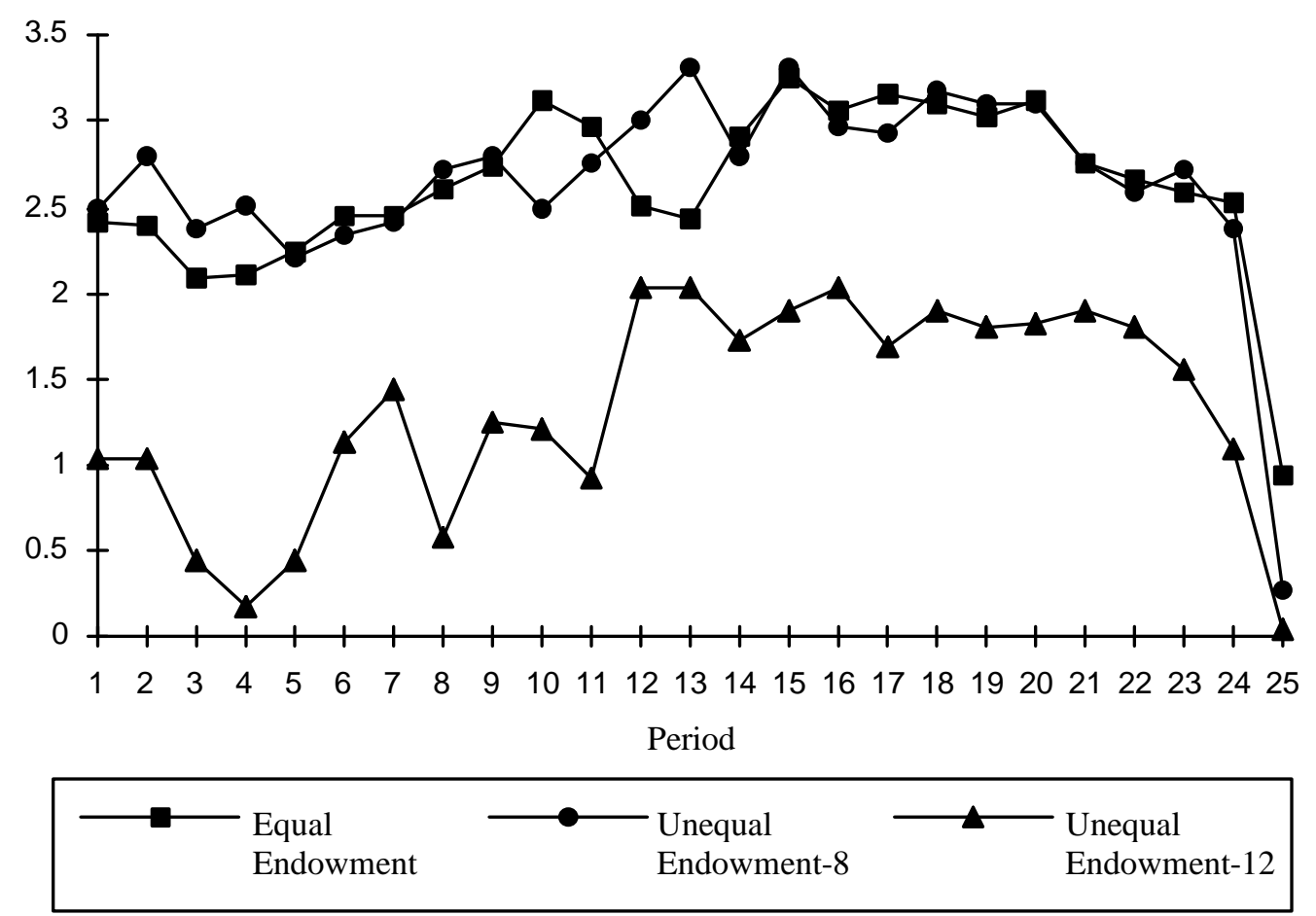

Figure 1. Average contribution level to the public good per period. The number of tokens allocated to the public account according to the dominant strategy is subtracted to make the different conditions comparable.

\footnotetext{
${ }^{5}$ As a consequence, subjects with a 12-marker endowment earned on average more than subjects with an 8-markers endowment. The difference (5.77 Dutch guilders) is statistically significant (Wilcoxon ranktest 2-tailed $\mathrm{P}=.0001$ ).
} 


\section{Social ties}

The main question of this study is whether social ties develop as a result of interaction in a repeated public good game. The idea is that the degree of success of the interaction in the public good game may influence the attitude towards the partner in the public good game, compared with the individual's general social value orientation. The degree of success in the public good game can be operationalized by the earnings in the game ${ }^{6}$. Table 2 shows the results of linear regressions where the angle measured by the second Ring-test is the dependent variable, and the social value orientation (angle measured by the first Ring-test) and the earnings in the last 5 periods of the public good game are the independent variables. Apparently the score on the second Ring-test correlates highly with the score on the first one. Earnings in the public good game have an additional positive effect on the score of the second Ring-test. This suggests that subjects who have earned well (not well) have a tendency to "like" ("dislike") their partners. So, it seems that social ties are formed through the interaction in the public good game.

A few remarks are in order. First, results are qualitatively the same if we use other measures of success in the public good game such as the other's contributions in the last 5 periods or earnings in all periods, but the fit is much weaker. Second, on average negative social ties were formed, since the average angle slightly decreased $\left(-3.8^{\circ}\right)$. Apparently, many subjects were (slightly) disappointed by the interaction in the public good game. Third, the impact of the public good game depends on the social value orientation. For example, in case of an individualist (angle is zero) a Nash equilibrium in the public good game results in no social tie, and positive contributions (in excess of the dominant strategy) of the other result in a positive social tie. For a cooperator (angle is $45^{\circ}$ ) the Nash equilibrium results in a negative social tie, and higher contributions are needed to result in a positive tie.

Table 2. Linear regressions with the angle measured by the second Ring-test as dependent variable and, as independent variables, the social value orientation (angle measured by the first Ring-test) and earnings in the last 5 periods of the public good game.

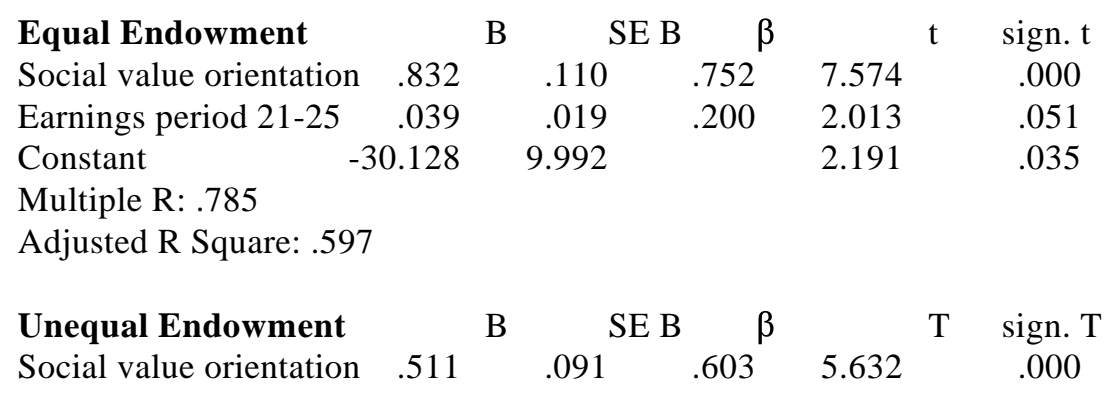

\footnotetext{
${ }^{6}$ An alternative would be to use a subject's value orientation to calculate her/his measure of success as a weighted average of own and other's earnings. Note, however, that for prevalent value orientations between $-45^{\circ}$ and $+45^{\circ}$ these measures always correlate positively with own earnings. Due to the development of social ties, measures based on the first ringtest are only relevant in early periods of interaction.
} 


$\begin{array}{lrrrrr}\text { Earnings period 21-25 } & .027 & .012 & .241 & 2.247 & .029 \\ \text { Constant } & -20.519 & 8.253 & & 5.815 & .000\end{array}$

Multiple R: .704

Adjusted R Square: .474

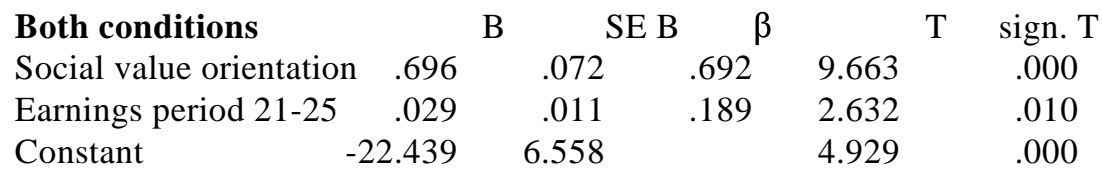

Multiple R: .743

Adjusted R Square: .542

Note: Only subjects with consistencies higher than 600 are included. 
Adaptive play in the public good game

It is very clear from the data that subjects reacted to the decisions of their partner during the 25 periods. Table 3 shows that an increase (decrease) of the contribution by the partner is typically answered by an increase (decrease) in the own contribution. These reactions can be interpreted as providing evidence for a continuous development of social ties ${ }^{7}$, but they may also (partly) represent some form of strategic behavior.

Table 3. Reactions of subjects to an observed change in the contribution to the public good by their partner in the previous period.

\begin{tabular}{llll} 
Contribution partner & \multicolumn{3}{l}{ Reaction on contribution by partner in previous period } \\
in previous period & decreases & same as previous & increases \\
decreased & $42.4 \%(241)$ & $33.0 \%(188)^{*}$ & $24.6 \%(140)$ \\
same as previous & $20.1 \%(261)$ & $65.1 \%(845)$ & $14.9 \%(193)$ \\
increased & $15.0 \%(99)$ & $36.1 \%(239) * *$ & $48.9 \%(324)$
\end{tabular}

* in 10 cases the contribution to the public account is 0 and stays 0

** in 27 cases the contribution is already maximal and stays so

\section{The influence of the last period on the social tie}

Social ties between partners are developed in the 25 periods of the public good game. However, the very last period is typically rather turbulent (the contribution level often drops dramatically). Therefore, the last period may influence the social tie more than any other period. Subjects may feel "cheated" if a partner plays the dominant strategy in the last period, or contributes less than in the 24th period. If we define "cheating" in this way, than in most cases both partners cheated, and on average negative social ties resulted (see table 4). If somebody did not cheat, but the partner did, an more negative social tie developed, whereas the social tie of the cheater did not change. If both partners did not cheat, a positive social tie was created. Interestingly, although the results of the last period seem to have a substantial impact on the social tie, they do not completely overshadow the other periods. In regressions like those in table 2 , the last period performs less well (in terms of significance) than the last 5 periods or all periods.

Table 4. Effect of last-period cheating on social ties.

\begin{tabular}{lllllc} 
& & effect & \multicolumn{2}{c}{ Mean change Number } \\
Who cheated? & positive & neutral & negative & in angle & of cases \\
Both cheated & $35 \%$ & $12 \%$ & $43 \%$ & -4.40 & 60 \\
Only the other cheated & $25 \%$ & & $75 \%$ & -8.08 & 12 \\
Only the subject cheated & $40 \%$ & $27 \%$ & $33 \%$ & -.86 & 15 \\
Nobody cheated & $40 \%$ & $20 \%$ & $40 \%$ & 7.13 & 5
\end{tabular}

Note: By definition somebody cheated if in the last period (s)he played the dominant strategy or contributed less to the public good than in the 24th period. Only subjects with consistencies larger than 600 are included.

\footnotetext{
${ }^{7}$ A higher contribution by the other leads to a more positive sentiment which induces an increase in one's own contribution, and vice versa.
} 


\section{Conclusion}

In this paper we investigated whether the development of social ties can be established in an experiment. Through interaction people form positive or negative sentiments about each other, dependent on whether the interaction is positively or negatively valued. Sentiments are here considered to represent the extent to which individuals care about the well-being of others. This establishes a relationship between the sociological notion of a social tie (which concerns a specific other) and the psychological notion of a social value orientation (concerning distributional preferences involving an arbitrary, generalized other). Psychologists have been successful in measuring social value orientation by using so-called decomposed game techniques, such as the Ring-test. Our results corroborate the validity and reliability of this test. However, the gist of this paper is that by applying the test twice -before and after an experiment with interaction - the development of social ties may be traced, given the aforementioned relationship between the two concepts.

Our main result is that we find, indeed, clear evidence of the development of (positive and negative) social ties in a public good experiment, under different experimental conditions. Subjects are more willing to help (hurt) another subject if their interaction with this individual has been more (less) advantageous to them. As a matter of fact, this willingness not only shows up in their allocation of real money in the second (ex post) test. It also manifests itself in their answers to the debriefing question whether they would like to be matched again with the subject they were paired with in the public good experiment, if the experiment were to be repeated, or with an arbitrary other subject. Further support for our results was presented at the 1996 ESA-meeting by Martin Sefton ${ }^{8}$.

Readers may wonder how these results relate to the reciprocity found in other studies (e.g. Fehr et al. 1993, 1994). In part 2 of the experiment, the public good game, we also found that behavior tends strongly towards reciprocity. However, this tells us nothing about the underlying mechanism. Such behavior may be driven by the development of social ties, by strategic considerations or by moral reasons (social norms) ${ }^{9}$. While there are possibilities for strategic behavior in the public good game, it cannot occur in the first and third part of the experiment. Thus, strategic behavior cannot explain the changes in the Ring-tests. If acting according to norms is mediated by sentiments, social norms are not a separate explanation of behavior, but part of the social-ties dynamic. However, if the behavior in the second Ring-test is driven by a social norm -

\footnotetext{
${ }^{8} \mathrm{He}$ commented on our paper and re-analyzed a different data set for this purpose. The data are from Morgan and Sefton (1996) where participants are matched with the same subject for 10 rounds to play a standard public good game, and after that they play an 11th round against another subject. Using pairs as unit of observation, Sefton takes contributions in round 11 as a proxy for social value orientation, and average earnings over rounds 1-9 as a measure of successful interaction. A regression of contributions in round 10 on these two variables shows a significant positive influence of the latter. Although this experiment was not designed for this purpose, and the endogeneity of the value orientation proxy may be a problem, the results are strikingly in line with ours.

${ }^{9}$ Cf. Sugden (1984).
} 
not mediated by sentiments - to punish or reward others, then this implies that also a social norm must exist which defines "good" (to be rewarded) and "bad" (to be punished) behavior in the public good game. Such a shared norm is unlikely because of the individual differences in social value orientation and because of the few contributions made in the last periods of the public good game. If shared social norms exist at all in this context, they seem to have little impact. Therefore we conclude that social ties play a crucial role.

The present experiment only allows for minimal interaction during a short period of time. Even in this setting the development of social ties was observed. Many economic phenomena take place over longer periods of time and involve richer interaction, so we expect social ties to be of even greater importance in these situations. 


\section{References}

Baumeister, R.F. and Leary, M.R. (1995). The need to belong: desire for interpersonal attachments as a fundamental human motivation. Psychological Bulletin 117, 497-529.

Coleman, J. S. (1990). Foundations of social theory. Harvard University Press, Cambridge.

Dehue, F.M.J., C.G. McClintock and W.B.G. Liebrand (1993). Social value related response latencies: inobtrusive evidence for individual differences in information processing. European Journal of Social Psychology 23, 273-293.

Fehr, E., G. Kirchsteiger, and A. Riedl (1993). Does fairness prevent market clearing? An experimental study. Quarterly Journal of Economics 108, 437-460.

Fehr, E. and G. Kirchsteiger (1994). Inside power, wage discrimination and fairness. The Economic Journal 104, 571-583.

Fararo, T. J., 1989, The meaning of general theoretical sociology (Cambridge University Press, Cambridge).

Feld, S. L., 1981. The focused organization of social ties. American Journal of Sociology 86, 1015-1035.

Granovetter, M. (1973). The strength of weak ties. American Journal of Sociology 78, 1360-1380.

Granovetter, M. (1985). Economic action and social structure: the problem of embeddedness, American Journal of Sociology 91, 481-510.

Granovetter, M. (1992). The sociological and economic approaches to labor market analysis: a social structural view, in: Granovetter, Mark and Swedberg, Richard, The sociology of eonomic life (Westview Press, Boulder).

Griesinger, D.W. and J.W. Livingston (1973). Toward a model of interpersonal motivation in experimental games. Behavioral Science 18, 173-188.

Homans, G. C. (1950). The human group. Harcourt, Brace and World, New York.

Homans, G. C. (1961). Social behaviour; its elementary forms. Routledge \& Kegan Paul, London.

Ledyard, J. (1995). Public goods: a survey of experimental research. In: The Ha ndbook of Experimental Economics (ed. A roth and J. Kagel), pp 111-181. Princeton, N.J.: Princeton University Press.

Liebrand, W. B.G. (1984). The effect of social motives, communication and group sizes on behavior in an n-person multi stage mixed motive game. European Journal of Social Psychology 14, 239-264.

Morgan, J. and Sefton, M., 1996, Funding public goods with lotteries: an experiment, mimeo.

Offerman, T. (1996). Beliefs and Decision Rules in Public good Games. PhD dissertation University of Amsterdam.

Offerman, T., J. Sonnemans and A. Schram (1996). Value orientations, expectations and voluntary contributions in public goods. Economic Journal 106, 817-845.

Sonnemans, J., A. Schram and T. Offerman (1996). Public good provision and public bad prevention: the effect of framing. Forthcoming in: Journal of Economic Behavior and Organization.

Sugden, R. (1984). Reciprocity: the supply of public goods through voluntary contributions. Economic Journal 94, 772-787.

Van Dijk, F. and F. van Winden. (forthcoming). Dynamics of social ties and public good provision. Journal of Public Economics.

Warr, P.G. (1982). Pareto optimal redistribution and private charity. Journal of Public Economic 19, 131-138.

Weimann, J. (1994). Individual behavior in a free riding experiment. Journal of Public Economics 54, 185-200.

Wellman, B. (1988). Structural analysis: from method and metaphor to theory and substance. In: Wellman, Barry and Berkowitz, S.D.. Social structures: a network approach. Cambridge University Press, Cambridge. 
Appendix 1

The 32 questions of the Ring-test

\begin{tabular}{llrrrr} 
number question & \multicolumn{2}{c}{ Alternative A } & \multicolumn{2}{c}{ Alternative B } \\
part 1 & part3 & self & other & self & other \\
1 & 32 & 000 & +500 & +304 & +397 \\
29 & 5 & +304 & +397 & +354 & +354 \\
4 & 2 & +354 & +354 & +397 & +304 \\
24 & 29 & +397 & +304 & +433 & +250 \\
15 & 22 & +433 & +250 & +462 & +191 \\
30 & 3 & +462 & +191 & +483 & +129 \\
9 & 16 & +483 & +129 & +496 & +65 \\
10 & 24 & +496 & +65 & +500 & 0 \\
5 & 13 & +500 & 000 & +496 & -65 \\
12 & 25 & +496 & -65 & +483 & -129 \\
22 & 6 & +483 & -129 & +462 & -191 \\
23 & 26 & +462 & -191 & +433 & -250 \\
21 & 1 & +433 & -250 & +397 & -304 \\
16 & 8 & +397 & -304 & +354 & -354 \\
11 & 9 & +354 & -354 & +304 & -397 \\
13 & 28 & +304 & -397 & 000 & -500 \\
7 & 31 & 000 & -500 & -304 & -397 \\
32 & 19 & -304 & -397 & -354 & -354 \\
18 & 17 & -354 & -354 & -397 & -304 \\
2 & 4 & -397 & -304 & -433 & -250 \\
28 & 20 & -433 & -250 & -462 & -191 \\
8 & 15 & -462 & -191 & -483 & -129 \\
27 & 21 & -483 & -129 & -496 & -65 \\
25 & 11 & -496 & -65 & -500 & 0 \\
19 & 23 & -500 & 000 & -496 & +65 \\
26 & 12 & -496 & +65 & -483 & +129 \\
17 & 7 & -483 & +129 & -462 & +191 \\
31 & 27 & -462 & +191 & -433 & +250 \\
6 & 14 & -433 & +250 & -397 & +304 \\
20 & 18 & -397 & +304 & -354 & +354 \\
3 & 30 & -354 & +354 & -304 & +397 \\
14 & 10 & -304 & +397 & 000 & +500
\end{tabular}




\section{Appendix 2 \\ Translation of instructions of part 2 (Public good experiment)}

To save space, we only present the instructions of the equal endowment condition, which are almost completely the same as for the unequal endowment condition.

\section{Introduction}

In a moment you will see the instructions for the second part of the experiment on your computer screen. Your decisions will again have financial consequences for you. These consequences can be read from the summary that I will show now via the overhead projector and distribute to you on a handout. The use of this summary will be explained in the instructions.

We start now with the instructions.

\section{Welcome at the practice program of part 2}

PART 2 of the experiment consists of 25 periods. In each period you are asked to make a decision. This decision always concerns the distribution of 10 markers over two activities: activity X and activity $\mathrm{Y}$.

Activity X leads to a payoff for yourself only. Activity Y leads to a payoff not only for yourself but also for another participant. This other participant has to take similar decisions: activity X leads to a payoff for her- or himself only. Activity Y leads to a payoff not only for this participant but also for you. After each period you are informed about the decision of the other. During the whole part 2 you are paired with the same person. You will be paid after the end of the experiment.

To avoid any misunderstanding: the participant you will be paired with is not the same as the 'other' in PART 1 of the experiment. PART 1 and PART 2 are completely independent of each other.

Before starting PART 2, you are now first asked to go through some exercises. We want to make sure that this part of the experiment is clear to you. In case of any questions, please raise your hand, and we will come to your table.

\section{$<$ After each exercise subjects had the option to go to the next or to return to previous exercises.>}

\section{Payoff information}

The upper-left corner of the screen shows you a summary of how your payoffs from the activities $\mathrm{X}$ and $\mathrm{Y}$ are determined. This is illustrated hereafter.

Your payoff from activity $\mathrm{X}$ depends on the number of markers that you yourself spend on this activity. The column "value" shows the payoff of each marker that you spend on activity X. As you see, every extra marker pays you less.

The column "sum" shows you the total payoff for each number of markers that you spend on activity X. If you do not spend any marker on activity $\mathrm{X}$ your payoff from this activity will be zero.

Your payoff from activity $\mathrm{Y}$ depends on the total number of markers that you and the other participant spend on this activity. Each marker pays you AND the other participant 14 cents.

In each period some costs will be subtracted from your payoffs, namely 110 cents. Thus, your total earnings per period will be: the payoff from activity X PLUS the payoff from activity Y MINUS the costs (110 cents). On your handout "Summary of Payoffs and Costs per Period" you find the same information as you can see now in the upper-left corner of your screen.

\section{Making a decision}

We will now practice how decisions are taken. At the bottom of the next screen you are instructed how to type your decision. In the upper-right corner you will see the DECISION-WINDOW. In this window you type in the number of markers that you want to spend on activities $\mathrm{X}$ and $\mathrm{Y}$. The decision-window appears on your screen at the beginning of each period.

First you type in how many of your 10 markers you want to spend on activity X. This number must be between 0 and 10 and should always be typed as two figures: 00, 01, 02,..,10. Then, press the Enter-key and type in your decision concerning activity $\mathrm{Y}$ in the same way. Note that the two numbers, for $\mathrm{X}$ and $\mathrm{Y}$, should add up to 10. Thereafter, press again the Enter-key. You will then be asked to confirm your decision. After confirmation you cannot change your decision anymore.

\section{Registration-table}


Below, you see now the REGISTRATION-TABLE. In this table your decision and the results are registered. This table will always be visible. The decision you have just taken is now registered for period Test 1.

\section{The decision of the other}

You have now taken a decision regarding the distribution of your markers. Your payoff from activity $Y$ in a period is co-determined by the markers that the other participant spends on $\mathrm{Y}$ in that period. To show this, we ask you now in this exercise to choose yourself a number for the markers that the other participant has spent on Y. Note that this number cannot exceed 10, since the other participant has no more markers than 10. Choose a number and press then the Enter-key.

\section{Registration-table}

You see now in the REGISTRATION-TABLE how the decision of the other participant is registered. In this exercise this is the number that you just chose.

We want to make sure that you fully understand what is registered in the registration-table. Therefore, we ask you now a few questions.

$<$ questions plus feedback about the determination and registration of payoffs, followed by 2 individual practice rounds>

During the experiment you will only see the results of the LAST period in the registration-table. However, you can use the PageUp- and PageDown-keys to look up earlier results. Your total earnings from all past periods are shown at the bottom of the registration-table. Also for this part of the experiment it holds that your earnings will be paid to you, confidentially and in cash, after the whole experiment is finished.

\section{End of exercises}

You are now ready with the exercises. We wait until all the participants are ready. 
Appendix 3

SUMMARY OF PAYOFFS AND COSTS PER

PERIOD

PAYOFF OF MARKERS FOR X

\begin{tabular}{|l|l|l|}
\hline MARKER & $\begin{array}{l}\text { VALUE } \\
\text { PER } \\
\text { MARKER }\end{array}$ & SUM \\
\hline 1 & 27 & 27 \\
\hline 2 & 25 & 52 \\
\hline 3 & 23 & 75 \\
\hline 4 & 21 & 96 \\
\hline 5 & 19 & 115 \\
\hline 6 & 17 & 132 \\
\hline 7 & 15 & 147 \\
\hline 8 & 13 & 160 \\
\hline 9 & 11 & 171 \\
\hline 10 & 9 & 180 \\
\hline
\end{tabular}

PAYOFF OF MARKERS FOR Y

\begin{tabular}{|c|c|c|}
\hline MARKER & $\begin{array}{l}\text { VALUE } \\
\text { PER } \\
\text { MARKER }\end{array}$ & SUM \\
\hline 1 & 14 & 14 \\
\hline 2 & 14 & 28 \\
\hline 3 & 14 & 42 \\
\hline 4 & 14 & 56 \\
\hline 5 & 14 & 70 \\
\hline 6 & 14 & 84 \\
\hline 7 & 14 & 98 \\
\hline 8 & 14 & 112 \\
\hline 9 & 14 & 126 \\
\hline 10 & 14 & 140 \\
\hline 11 & 14 & 154 \\
\hline 12 & 14 & 168 \\
\hline 13 & 14 & 182 \\
\hline 14 & 14 & 196 \\
\hline 15 & 14 & 210 \\
\hline 16 & 14 & 224 \\
\hline 17 & 14 & 238 \\
\hline 18 & 14 & 252 \\
\hline 19 & 14 & 266 \\
\hline 20 & 14 & 280 \\
\hline
\end{tabular}

\section{COSTS PER PERIOD: 110 CENTS}

Explanation: You distribute your budget of 10 markers over X and Y. Your payoff from activity X only depends on the number of markers that you yourself spend on this activity. In the column "SUM" of the left table you see the payoff of each number of markers that you spend on activity X. If you do not spend any marker on activity $\mathrm{X}$, your payoff from this activity is zero.

Your payoff from activity Y depends on the total number of markers that you and the other participant spend on this activity. Each marker gives you AND the other participant a payoff of 14 cents, irrespective whether the markers comes from you or the other participant. In the column "SUM" of the right table you see the payoff from activity Y.

In each period 110 cents are subtracted from your payoffs as costs. Your total earnings per period are, thus: your payoff from activity X plus your payoff from activity $\mathrm{Y}$ minus the costs of 110 cents.

For example, if you spend 4 markers on $\mathrm{X}$ and 6 markers on $\mathrm{Y}$, and the other participant spends 8 markers on Y, then your total earnings are equal to 182 cents, namely 96 (payoff of 4 markers for X) plus 196 (= payoff from $6+8=14$ markers for $Y$ ) minus the costs of 110 . 
In the table below your total earnings are shown for all possible combinations of your decisions and the decisions of the other participant. We show this table because sometimes participants prefer it. You need not use this table; you can also compute your earnings yourself, if prefer to do so.

TOTAL EARNINGS TABLE

(figures in cents)

\section{MARKERS OF THE OTHER PARTICIPANT}

\begin{tabular}{|l|l|l|l|l|l|l|l|l|l|l|l|l|l|}
\multicolumn{1}{c|}{} & $\mathrm{X}$ & 10 & 9 & 8 & 7 & 6 & 5 & 4 & 3 & 2 & 1 & 0 \\
\hline $\mathrm{X}$ & $\mathrm{Y}$ & 0 & 1 & 2 & 3 & 4 & 5 & 6 & 7 & 8 & 9 & 10 \\
\hline 10 & 0 & 70 & 84 & 98 & 112 & 126 & 140 & 154 & 168 & 182 & 196 & 210 \\
\hline 9 & 1 & 75 & 89 & 103 & 117 & 131 & 145 & 159 & 173 & 187 & 201 & 215 \\
\hline 8 & 2 & 78 & 92 & 106 & 120 & 134 & 148 & 162 & 176 & 190 & 204 & 218 \\
\hline 7 & 3 & 79 & 93 & 107 & 121 & 135 & 149 & 163 & 177 & 191 & 205 & 219 \\
\hline 6 & 4 & 78 & 92 & 106 & 120 & 134 & 148 & 162 & 176 & 190 & 204 & 218 \\
\hline 5 & 5 & 75 & 89 & 103 & 117 & 131 & 145 & 159 & 173 & 187 & 201 & 215 \\
\hline 4 & 6 & 70 & 84 & 98 & 112 & 126 & 140 & 154 & 168 & 182 & 196 & 210 \\
\hline 3 & 7 & 63 & 77 & 91 & 105 & 119 & 133 & 147 & 161 & 175 & 189 & 203 \\
\hline 2 & 8 & 54 & 68 & 82 & 96 & 110 & 124 & 138 & 152 & 166 & 180 & 194 \\
\hline 1 & 9 & 43 & 57 & 71 & 85 & 99 & 113 & 127 & 141 & 155 & 169 & 183 \\
\hline 0 & 10 & 30 & 44 & 58 & 72 & 86 & 100 & 114 & 128 & 142 & 156 & 170 \\
\hline
\end{tabular}

Note that in each cell the total earnings are shown that you will get if that combination is chosen by you and the other participant. For example, if you divide your budget of 10 markers into 8 markers for $\mathrm{X}$ and 2 markers for $\mathrm{Y}$, and the other participant divides her or his budget of 10 markers into 5 markers for X and 5 markers for $\mathrm{Y}$, then your total earnings are 148 cents. These are your actual earnings. You do no longer have to subtract the costs of 110 cents. 